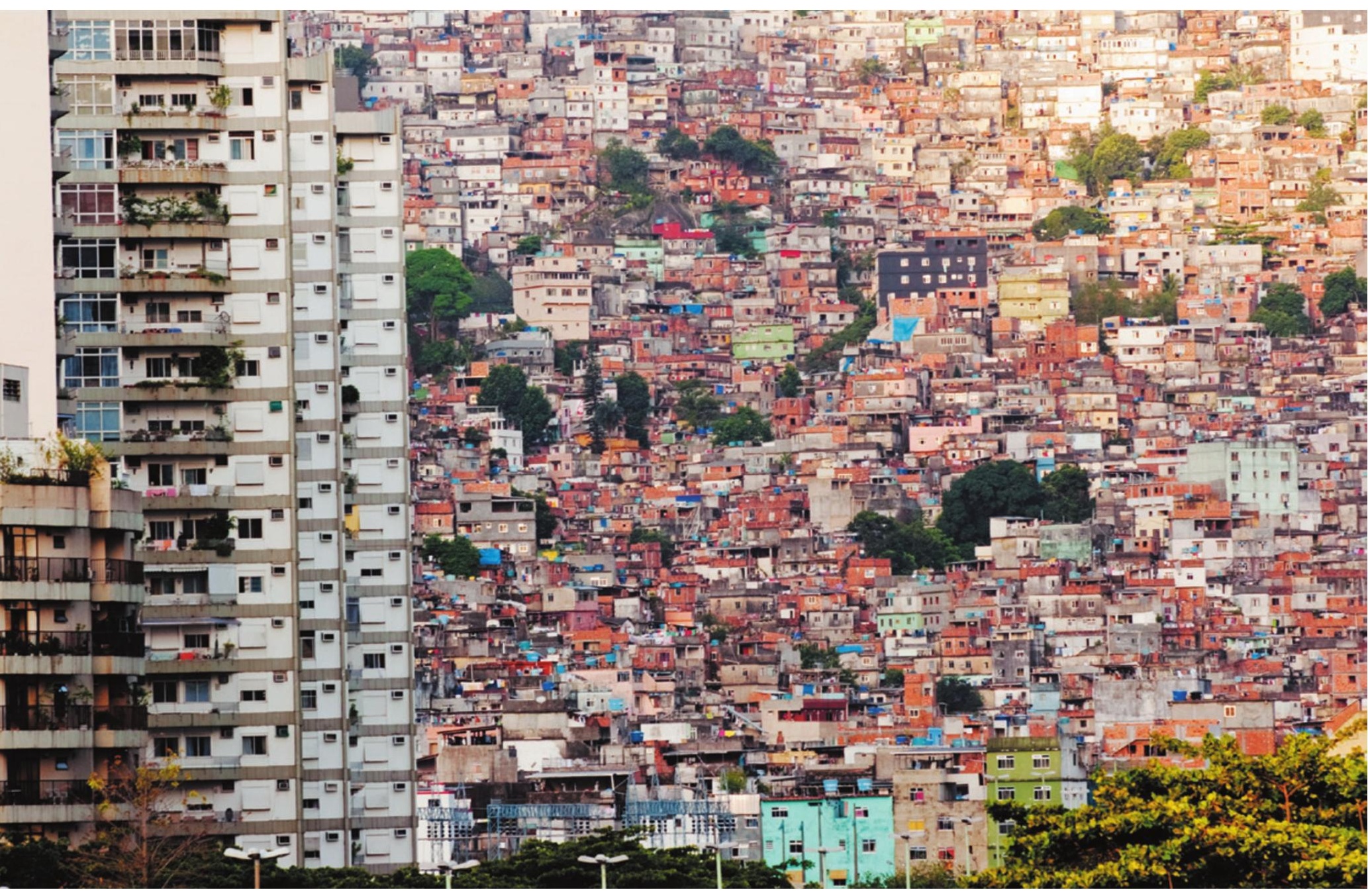

High-rise apartments tower in front of a breeze-block sprawl in Rio de Janeiro, Brazil.

\title{
Crowd control
}

\section{Hania Zlotnik assesses two polarized takes on population growth and planetary capacity.}

$\mathrm{I}$ e, the United Nations Population Division announced that the world's population could grow from 7.2 billion today to 9.6 billion by 2050 , assuming that global fertility continues to decline. Such growth constitutes a fundamental challenge for humanity, and now two thoughtful but very different takes on it explore the implications.

In Countdown, Alan Weisman, a journalist probing whether a sustainable balance between nature and the human population can be achieved, offers a key message to guide future action. He avers that no matter what environmental, ecological or social problem we face, it will be easier to solve with fewer people. His book provides an array of examples on how to reduce population growth
10 Billion

Allen Lane: 2013.

Countdown: Our Last, Best Hope for

a Future on Earth?

Little, Brown: 2013. requisite for achieving a sustainable future.

Stephen Emmott's 10 Billion takes for granted that the population will continue to grow, and is much less sanguine about humanity's chances of avoiding looming crises. Emmott, head of computational science for Microsoft Research in Cambridge, UK, leads an interdisciplinary group of scientists engaged in addressing fundamental problems through complex modelling. His slim, even terse book based on his 2012 stage show, which presented his view on the "unprecedented planetary emergency we've created" - primarily examines the transformation of the global environment by human activity, a transformation that includes climate change, increasing water shortages and growing urbanization. Emmott's assessment of the capacity of people and technology to prevent the global crises that confront us is grim.

Weisman's book, by contrast, offers hope. Countdown emphasizes that it is possible to curb population growth by voluntarily limiting family size. He describes how societies as different as those of Costa Rica, Iran, Japan, Kerala in India, and Thailand, have 
managed to reduce the number of children per woman through the voluntary use of contraception, buttressed by strategies to promote the adoption of a small-family norm - for example, by engaging opinion makers such as government leaders, religious authorities and media icons. Weisman explains that providing contraceptives to the quarter of a billion women worldwide who wish to prevent pregnancy but are not using effective contraception would be the first order of business.

It will also be essential to shift attitudes away from prizing high fertility. To illustrate the barriers preventing rapid fertility reductions, Weisman cites the examples of Gaza, Niger, Pakistan and the Philippines, where a combination of religious beliefs, pro-natalist ideologies, the low status of women, weak health systems and a lack of easy access to effective contraception can lead to an average of five or more children per woman. He describes in harrowing detail the consequences of persistent high fertility, with respect to both its detrimental effects on the well-being of individuals and the negative impact of rapidly increasing numbers of people on the survival of other species and the integrity of essential ecosystems.

An important part

"Weisman describes in harrowing detail the consequences of persistent highfertility." of the narrative in Countdown hinges on how past predictions of an imminent population collapse caused by limitations in natural resources have not come to pass, largely because technology has removed those limitations, at least temporarily. Both 10 Billion and Countdown provide ample evidence that such revolutionary technology is itself causing new forms of environmental stress. The strains of wheat and rice that led to the 'Green Revolution', for instance, made it possible to feed an ever-growing world population; but the crops are thirstier, which is depleting water reserves, and also demand the use of fertilizers, which are a source of pollution.

Both Emmott and Weisman consider that curbing consumption is essential for long-term sustainability, and both despair at the lack of a concerted effort to achieve it. Whereas Emmott does not present ways to address our failures, Weisman's emphasis on expanding access to contraception as the next-best strategy is both pragmatic and workable, as past efforts have shown. It is to be hoped that his message may be heeded sooner rather than later.

Hania Zlotnik is a population specialist. She is the former director of the United Nations Population Division. e-mail:hania.zlotnik@hotmail.com

\section{Books in brief}

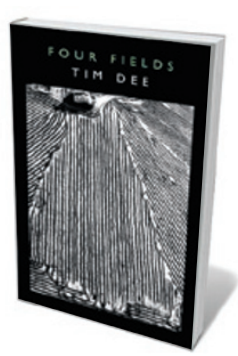

\section{Four Fields}

Tim Dee JONATHAN CAPE (2013)

In this vivid 'field study', radio producer and nature writer Tim Dee explores four plots of land, in England, Ukraine, the United States and Zambia. To Dee, these are grassy arenas where nature and humanity clash and merge. He is a fiercely focused witness to that drama, whether monitoring grasshoppers in the irradiated zone around Chernobyl, or on a Cambridgeshire fen listening to cuckoos calling, "deepening the place, summoning the curve of the Earth". With a lyricism richly and strangely his own, Dee maps a topography that has as much to do with the mind as with Earth.

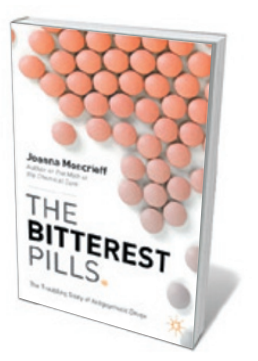

The Bitterest Pills: The Troubling Story of Antipsychotic Drugs Joanna Moncrieff PALGRAVE MACMILLAN (2013)

Psychiatrist Joanna Moncrieff delivers a meticulous, balanced history of antipsychotic drugs. In the mid-twentieth century, early forms such as chlorpromazine were created to tackle the biological roots of severe mental illness. But as she shows, new-generation 'atypicals' are marketed to treat conditions such as depression, and US spending on antipsychotics reached almost US\$17 billion in 2010. Moncrieff sees some antipsychotics as having a place in treating schizophrenia, but argues that questions about efficacy and side effects such as obesity suggest they should be handled with care.

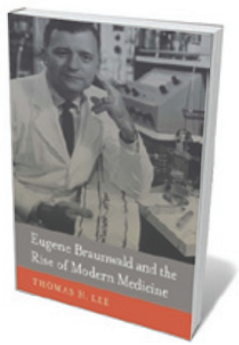

\section{Eugene Braunwald and the Rise of Modern Medicine}

Thomas H. Lee HARVARD UNIVERSITY PRESS (2013)

A pioneering 1971 study on myocardial infarction revealed that a heart attack is a process rather than a sudden karate chop, and hence eminently treatable. Eugene Braunwald's finding has helped to cut US heart-attack death rates from more than $30 \%$ to less than $10 \%$. The story of the cardiologist's life and work, set against a background of rapid change in medicine, is told engagingly by medic Thomas Lee. Braunwald has lived several lives since his 1938 escape from Nazi-controlled Austria, from glory years at the US National Institutes of Health to his active ninth decade.

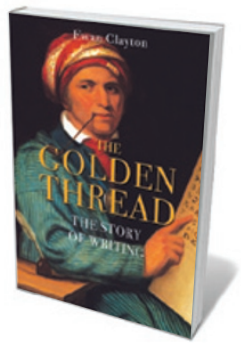

The Golden Thread: The Story of Writing

Ewan Clayton ATLANTIC (2013)

Calligrapher Ewan Clayton examines one of the earliest forms of communications technology: writing, from its inked and incised beginnings some 5,000 years ago to its digitized present. Clayton, who advised Xerox Corporation's Palo Alto Research Center in California on the use of documents, is erudite on everything from Herculaneum's ancient election 'posters' to contemporary German graffiti. Here too are Isaac Newton's first notebook, the geometry of pen nibs, 'muscular penmanship' in the nineteenth-century United States - and a palpable relish for the dance of words on a page.

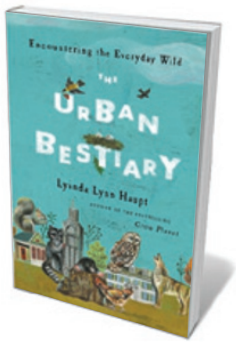

The Urban Bestiary: Encountering the Everyday Wild

Lyanda Lynn Haupt LITTLE, BROWN (2013)

From coyotes in lifts to woodpecker holes in the Discovery space shuttle, odd encounters at the nature-human interface abound in this 'bestiary'. But naturalist Lyanda Lynn Haupt has a serious agenda, arguing that an appreciation of the displaced beasts re-entering our porous cities is crucial to human well-being. As she recounts the precarious existence of an opossum or the "cognitive toolbox" of a crow, Haupt urges a new sensitivity towards urban wildlife. The taxa are US-centric; the message is universal. Barbara Kiser 